Bangladesh Journal of Bioethics 2012; 3(1):4-12

\title{
TRANSCENDING GENDER AND SEX: ETHICAL IMPLICATIONS FOR IDENTITIES, AMBIGUITIES AND INTERRELATIONS
}

\author{
Oluwaseun Adeola Adenugba \\ Department of Philosophy \\ Olabisi Onabanjo University \\ Ago-Iwoye, Ogun State, Nigeria. \\ Email: seunfunmiade@yahoo.com
}

\begin{abstract}
This paper examines the moral issues involved in the acts of transcending gender and sex. Attempts are made in answering such fundamental questions as: Is transgenderism necessary and beneficial? Does transsexualism necessarily imply transgenderism? Are natural rights violated by the acts of transcending sex and gender? What implications do development in trangenderism and transsexualism hold for our conventional linguistic resources, identity and interrelationships? Ought humans to be allowed freedom to choose to transcend gender and sex? What criteria should be used in avoiding bigotry against androgynous and in harmonizing relationships with their physician? We review the current state of clinical research with transsexualism and transgenderism, the history of transsexual research, the major moral arguments for and against the practices of transcending gender and sex, and the new ethical dilemmas sprawled as aftermath. The paper critically assesses the arguments on the dividing line of the debate. This paper establishes that the reasons offered for artificial intervention in traversing sex and gender are not sufficient and morally convincing enough. It concludes that instead of the predominant current attitude of aggressive intervention with naturally unique sexuality, together with its attendant discrimination and moral resentment against transsexuals and transgenders, it is more ideal to engage on the one hand, in an in-depth discussion with the concerned people, listen to their worries and see ways in which their problems could be addressed through counseling. An on the other hand, there is a need for public discourse and public awareness on the fluidity in gender and sexual orientation so that people's attitude to this new development can be better sharpened.
\end{abstract}

Keywords: Transgender, transsexualism, gender dyphoria.

INTRODUCTION: Transgenderism and transsexualism are relatively new issues generating opprobrium in contemporary ethical discourse. These acts generate some new worries beyond the conventional issues in gender and sexism discourses; this accounts for why we have divergent opinions as to the morality, immorality or amorality of transgenders and transsexuals. Starting off from a conceptual angle, this paper provides some analysis of related concepts that can enhance our subsequent understanding of the moral issues raised in this paper: transgenderism and transexualism. As a prelude to this, is a historical exposition of the genesis to the practices of transgenderism and transsexualism. The third section of this paper is a critical x-ray of the apologist arguments and the non-apologist stance on the ethics of transgenderism and transsexualism. The last section of the paper systematically evaluates the dividing line in the debate with some noteworthy concluding remarks. 
HISTORICAL ANALYSIS OF TRANSGENDERISM: The history of transgenderism shows that it was already in existence before it was diagnosed in the $19^{\text {th }}$ century. History reveals that modern diagnosis started back in 1880s in Germany. Dr. Magnus Hirschfeld was the true pioneer in the field of transgenderism and he was also the first to coin the two popular terms used in describing transgender: transvestism and transexualism. Though Cauldwell was quoted in about $98 \%$ literature as the first to use the word, Hirschfeld wrote his first monograph about this phenomenon in $1910^{1}$.

Hirschfeld's curiosity and interest for transgender made him explore the idea of a surgical solution to some of the cases of transgender. He also reported that the first incomplete surgery in female to male patient was performed in Berlin in 1912.This surgery involves the removal of the sexual organ of the patient. The most notable attempt at vaginosplasty was initially performed using skin graft from the legs. However, in 1931, the first male-female was again reported. This success was made possible with Hirschfeld's recommendation. This patient, named Ritchter Rudolph, underwent castration (Penectomy) and an artificial vagina was constructed for hir.

In 1930, Lili Elbe who was referred by Hirschfeld had sexual re-assignment surgery under Gohrbandt, and died the following year from the complications that resulted from the surgery. The death of Lili Elbe caused fear to the people as a result of which Magnus Hirschfeld Institute for Sexual Science was raided and destroyed by Nazis. Magnus Hirschfeld died two year after the incidence. The reaction of people to transgender prompted them to burn writings in sexology and this accounted for the reason why sexologists were persecuted during the Nazi holocaust. It is also very interesting to note that transexualism that was halted by German society was embraced by some countries in Europe.

In Demark and Norway, this activity is being referred to as 'therapeutic penectomies' and castration'. History recorded that transsexualism moved into public spotlight in late 70 s and early 80 s. This became very more evident when the first American named Christine Jorgensen had SRS (Sexual Reassignment Surgery) in 1952 which was done in Copenhagen. This incident attracted the attention of the public and it was also reported in New York Daily News. This publicity of the sexual reassignment of Christine Jorgensen made the practice to grow dramatically. As a matter of time passage, transsexuals began telling their own stories without any fear of contradiction or molestation.

However with the growing prevalence of SRS in Europe, the US was still hesitant to the operation. This was because transgender individual were afraid of being persecuted by law. SRS would remain a crime as long as there is no officially recognized diagnosis that makes it a valid cause. SRS finally came to America and the first Gender Identity Clinic was opened; but it was done after getting permission from Baltimore court. SRS today is a wider practice outside the continent of Europe to every part of the world.

\section{TRANSGENDER AND TRANSSEXUAL: A CONCEPTUAL CLARIFICATION:}

Karl H. Ulrichs once voiced that:

Our character, the manner in which we feel, our entire temperament is not masculine, it is feminine. We only act male. We play the male just as an actress plays a man on stage.... It is impossible for us to transform our female instinct into a male instinct ${ }^{2}$. 
The above alarm of Karl Ulrichs shows that transgender individuals are just unfortunately caught in a wrong body. As a transgender hirself and hir assertion represents the contradiction between hir sex assigned at birth, and hir gender disposition. There are a host of people who from an early childhood stage in life often show a desire to express themselves in ways that are not socially acceptable for their naturally assigned sex. If this true, what then is transgender?

Transgender can be described as a general term applied to a variety of individual behaviors and groups centered on the full or partial reversal of gender role ${ }^{3}$. Transgender individuals are people who by all known biologic measure are male or female yet feel like a member of the opposite sex ${ }^{4}$. Transgenderist are therefore people who freely and fully live in opposition to their anatomy. They are said to suffer certain discomfort and as a result of this may need their sex changed. This discomfort is called 'gender dysphoria'. However, transgender may or may not had medical re-assignment surgery called SRS i.e. Sexual Re-assignment Surgery while transsexuals are individuals who desire to have or have achieved, a different physical sex from that which they were assigned at birth. Transsexuals are those who had surgery or hormones enhancement in an attempt to traverse the boundary of their physical sex. They were assigned at birth. "A transsexual man may be referred to as FTM (female to male), F2M, or MTM, the latter used in recognition of the fact that they had not ever felt female in their lives" ${ }^{\text {". }}$. We can therefore say that all transsexuals are transgender but not all transgender are transsexual. Transgenderists are said to have long faced discrimination in medical institution, including physician's offices and hospitals ${ }^{5}$. More critical is the societal opprobrium against them; they are seen as outcast in many societies.

There are divergent views as to what may have caused a person to feel highly uncomfortable with the sex which hir/sie belongs. Can we simply say that transgender have a uniquely wired brain? What exactly is the cause of this? Are they different being entirely? These are some of the questions that lingers the mind of concerned persons about transgender.

A recent study showed that "the nucleic of transgendered male to female (MTFs) is the same size of the nuclei of genetic females" ${ }^{6}$. This position is further supported by an earlier study that reveals that female hormones have been used in treating prostate cancer for years so also is female dying of virilizing adrenal tumors has nucleic consistent with their genetic sex ${ }^{7}$. This is a way of saying that the hormonal exposure of both female and male has no effect on the gender specific nuclei of their brains.

In the psychiatric diagnosis coding manual DSM-IV, gender dysphoria is listed as a psychiatric condition. Psychopharmacologic medication is given to individual who has not had surgery. This medication i.e. psychopharmacologic medication may no longer be necessary once surgical intervention has taken place.

As earlier mentioned, transgenderists do not feel fit in the body they find themselves and nearly all transgendered adults feel this discomfort right from their childhood. This feeling comes from within and this is very difficult to say as a child. Some children even make effort to dress and act like a man secretly. The stage of acknowledgement of themselves as not being in the right body varies from mid childhood to middle age. Transgender people failed to acknowledge this fact because of the fear of being stigmatized in the society or the possibility of being rejected by their family, friends and even at their places of work. It seems this act naturally sounds absurd and difficult to convey proudly in the society.

Many have mixed up transgenderism with homosexuality. Homosexuals are individual who are sexually attracted to members of the same sex and may not have the desire to have their sex changed. Some of 
them are desirous of a change in sex. Those who have their sex changed (MTFs) still are attracted to men; much as FTMs are also attracted to women. Richard Green hypothesized that homosexual identity disorder is etiologically related to homosexuality without GID (Gender Identity Disorder)

It is worth noting that majority of the children who express interest in being the opposite sex are not transgender though many of them become homosexual and less than $20 \%$ of this children want to be called a name consistent with their gender identity ${ }^{8}$. This goes with their way of dressing, the kind of friends they move with and the kind of activities they engage in. Many of them are also afraid of the age of puberty because the irreversibility of this change is seen as a threat to the way they are perceived.

The rate at which medical practice is advancing is amazing and that is why "medicalization" of transgenderism is possible. "Medicalization" has helped transgendered people to acquire therapy and social acceptance, transgenderism is part of a larger social struggle between defenders of the "natural" and "God-given" and the right of individuals to control their own bodies and define their own lives ${ }^{9}$. Whether the individual has a sole right to intervene with the natural is another question entirely. In order to have a sex changed either from male to female or female to male required certain medical intervention. Estrogen is required from MTF and testosterone is required for FTMs. These interventions have their side effects. This shall be discussed later when pointing out the risks of SRS and treatments.

BIOMEDICAL ETHICS, TRANSSEXUALISM AND TRANSGENDERISM: In this session, effort will be made to analyze very critically, the practices of transexualism and transgenderism, using the principles of biomedical ethics as propounded by Tom Beauchamp and James Childress which are: the principle of respect for autonomy, the principle of beneficence, the principle of non-maleficence and the principle of justice. Our aim in this regard is to justify and defend acts in transsexualism and transgenderism.

Transgenderism, Transsexualism and the Principle of Respect for Autonomy: Autonomy is derived from the Greek word autos and nomos meaning self- rule or self-governance ${ }^{10}$. Initially, this principle was directed only in relation to self-rule of independent city or state; but now, it is extended to individuals. The autonomous individual acts freely without interference from the other. S/he chooses what s/he sees as being right. The conception of the scope of autonomy differs among scholars. Some recognize it as the capacity for self- governance such as understanding, reasoning, deliberating, managing, and independent choosing. At the level of the individual, the non-coerced demonstration of these capacities is seen as the trait of an autonomous person ${ }^{11}$. Being autonomous is to respect the moral agency of an individual; respecting individual agents is to acknowledge that they have a right to hold a view, make a choice and take actions based on their personal values and beliefs ${ }^{10}$.

If the principle of respect for autonomy is rightly taken, then an individual agent who has chosen a medical intervention for his/her discomfort should not be hindered in anyway. A transgender who suffers gender dyphoria has the moral right to determine what hir/sie wants to do with the body. As long as a discomfort is evident, no one should stand against the actualization of the desired goal of either an intending transsexual or a transgender. Denial of such is an infringement of the person's right and disrespecting his autonomy. Such an endeavor can be term as cruel. How do we know when an individual is indeed autonomous to make such big decision? This would raise further question on the criteria for autonomous being.

Transsexualism, Transgenderism and the Principle of Beneficence: It is one thing to respect individual autonomous decision; it is another to help others in the attainment of a beneficial end by contributing to their welfare. Beneficence refers to the character traits or virtue of being disposed to act for 
the benefit of others. The principle of beneficence therefore refers to a statement of moral obligation to act for the benefit of others ${ }^{10}$. With the principle of beneficence, one is not only refrained from harming, but also to make effort in doing what will benefit others. By implication, the principle of beneficence recognizes the moral obligation a person with the intent of transsexing owes others by self-querying whether the act will benefit others or not. To a transgenderist, the question is raised if the act of gender fluidity will be beneficial to other concerns, even if not self- beneficial to the transgendered. The principle of beneficence has an altruistic appeal though with modification. This principle of beneficence raises some questions, which if not cleared, may affect the right application of the moral principle to the acts of transcending sex and gender. What is best, and even beneficial, is itself, a problematic concept. It is arguable to say that I can only know what is best for me and not for others. What is beneficial to me may not be beneficial to others. In fact, the word 'others' is ambivalent as one may ask, what is the scope of the 'others'? In any case, conscious effort should be made to support an individual in actualizing what is beneficial to him and no effort should be made to hinder him from what he thinks benefits him. A transsexual who succeeds the surgical operation and hormones enhancement may want to belief hir/sie has benefited by being in the desired body.

Transsexualism, Transgenderism and the Principle of Non-maleficence: This principle imposes an obligation not to inflict harm on others. This principle in a way expresses an obligation of non maleficence and an obligation of beneficence which goes thus: "I will use treatment to help the sick according to my ability and judgment, but I will never use it to injure or wrong them" ${ }^{\text {"12. }}$ This principle can be simply stated thus: one ought not to inflict evil or harm, either on self or others. The denial of a transgendered individual the avenue to have SRS may be termed as doing harm to the other. The discrimination and resentment to health care that transsexual are prey to in the hands of the society and medical personnels are morally condemnable on the basis of the principle of non-maleficence because the transsexual or transgendered are psychologically and medically harmed. There are different ways in which an individual can be harmed. Harming could be psychological, emotional, physical and institutional. The strong feeling of being in the wrong body is a feeling that no one can assist another to explain with adequacy. It is a feeling that could be tagged with the psyche even emotional and this may affect the relationship of such individual with the other members of the society. How can we be sure that granting the request of transexualist is not more of infliction of harm on the concerned individual?

Transsexualism, Transgenderism and Principle of Justice: Various philosophers have used terms like fairness; desert and entitlement in an attempt to explicate justice ${ }^{10}$. Justice guarantees what is due or owned to a person. An act is considered as injustice if it involves a wrongful or an omission that denies people resource or protection to which they are due. Injustice is said to occur when some benefits to which a person is entitled are denied without good reason or when a burden is imposed unduly. The endeavor to kick against transsexualism could be said to be denying the concerned individual resource and the protection they are due for. In order to ensure that justice is done to everyone, transgender should not in any way be prevented from what he so desire to have or to be in life.

Our in-depth understanding of the analysis of the principles of biomedical ethics vis a vis transgenderism shows that it favors the act.

WHY NOT TRANSSEXUALISM AND TRANSGENDERISM: We shall critically present the ethical problems generated by the acts of transsexualism and transgenderism, which are arguments posed against the practices. Some arguments have been posed against the veracity and meaningfulness of the practice of transsexualism, be it Male to Female (MTF) or Female to Male (FTM): 
Evident danger: In traversing sex, (both in FTM or MTF), supraphysiologic doses of cross hormones is required for its effectiveness. For MTF, estrogen is required and FTMs, testosterone is required. The danger in this intervention is that the administration of high dose of estrogen poses the risk of blood clots. This is said to be very fatal if it travels to the lungs. Testosterone use for FTM is also with its risk. Testosterone is meant to prevent menses but this drug also induces hypertension.

Irreversibility: It may be important at this point to note that SRS is not just about changing sex, gender role or name. It involves changing everything that makes one either man or woman. For instance, the administration of estrogen to male changing to female has the effect of producing breast enlargement and also helps to diminish sperm production. This is the reason why some have decided to have their sperm stored in the sperm bank in order to maintain and retain their productive capacity. So also is ovulation and menses lost when testosterone is used. The unfortunate thing is that eggs cannot be stored but it is not impossible that it may be technologically possible in the nearest future. Our worry with this practice is that the change as a result of SRS is irreversible.

Intervention in children: Intervention in children also constitutes a very serious problem. There is the problem of when and how to intervene with children evaluated to be transgendered. There is no consensus as to what should be done to children with gender dyphoria. The worry is whether the intervention should come up at early age or withhold till when we can be sure that the child really wants it. Some have argued that such should be delayed until the completion of puberty because children are likely to have their minds changed about their sex; some others have argued that the earlier it is done, the better. This argument is defended on the ground that it will help to prevent severe depression and it will also help to avoid psychological effects resulting from painful procedure during and after intervention.

Integration in the society: Many are faced with the problem of how to address transgender individual. Since it is not the case that all transgender are transsexual, one may therefore be a transgender and not transsexual. The implication of this is that the practice creates ambiguity of identity. One may not find it funny making mistake in addressing transgender when only their gender role has been transitioned to a role consistent with their gender identity. This is because their name and gender have not been legally changed. In some states, before allowing a name and gender changes, "genitoplasty" or "mastectomy" may be required. This is a serious confusion caused by transgenderism.

Cost of treatment: This intervention is costly and most insurance companies do not cover this treatment. Many save for many years in order to have necessary treatment for the discomfort they suffer. In the Netherlands and Belgium, National health insurance covers treatment related to transgender individual. In short, the unequal access to treatment of transgender as it is not covered by all countries strengthens the harm done to the individual who could not access such ${ }^{13}$.

Playing God: The idea of playing God is prominent in arguing against all forms of human enhancement technologies. Activities such as genetic engineering, cloning, and reproductive technologies such as IVF, artificial insemination etc. are argued to be playing on God, or put mildly, rubbing shoulder with God in the act of creation. There is no doubt that activity such as this involves series of manipulations. In the other way, a counter argument can say that we are not playing God but assisting God to perfect the imperfection in what He has created. Since we are ordinarily meant to be creative and productive, there is no point waiting for God for remedies. Instead, conscious effort should be given in service to humanity in order to bring about perfection. 
Unnaturalness: There is also the argument that says it is naturally wrong to go against nature ${ }^{14}$. It is a traditional part of Catholic moral theology ${ }^{15}$. Since transsexualism is an act against the natural way in which the person has been created, conscious intervention is therefore morally wrong. Transsexualism is a form of enhancement. It is to make people be in their best. There is a counter argument against this position because defining "natural" itself is a difficult task to embark on. Almost all the technology we benefit from will be termed as unnatural. For instance, the use of mobile phone, airplanes etc. will all count as unnatural.

Other argument is that it increases inequality because not every transgender will be able to afford the cost of treatment and solutions to the discomfort suffer. SRS also opens up the opportunity for misuse to the extent parent can desire the opposite for their children especially when there are existing treatments to it.

Having carefully discussed the arguments against transsexualism, we have seen very clearly the problems with the practice. Additionally, Dr. Paul McHugh, a psychiatrist-in-chief of Johns Hopkins Hospital said:

I have witnessed a great deal of damage from sex-reassignment... we
psychiatrists have been distracted from studying the causes and
natures of their mental misdirection by preparing them for surgery and
for a life in the other sex. We have wasted scientific and technical
resources and damaged our professional credibility by collaborating
with madness rather than trying to study, cure, and ultimately prevent
$\mathrm{it}^{15}$.

McHugh realizes that efforts in the past made damaged their credibility by getting involved in preparing transgender individual for surgery. Elliot on the other hand compared SRS to a psychiatric condition. Like the conservative critique, Elliot argues that sex re-assignment is a sign that we are using inappropriately to cure spiritual and psychiatric ailments ${ }^{16}$. All these arguments show the controversial nature of transsexualism.

EVALUATION: Considering the arguments for and against earlier presented, it is crystal clear that the debate around transgenderism is an enigmatic one. Aside these arguments, there are certain cultural issues which seems not to be too evident for some culture but dominant in some others. For instance in an African culture specifically some parts of the Yoruba land (a tribe in South West, Nigeria) importance is placed on a male child. If transgenderism is culturally and generally accepted by the society, there is no doubt that members of the society may want their sex changed so that they can perfectly fit in. This, no doubt, may give them the necessary treatment they deserve as member of the desired sex. Cultural issues may be part of the reasons why some transgenders wants sexual reassignment surgery.

Besides cultural bias in the assessment of transgenderism and transsexualism, some scholars have based their arguments on freedom and autonomy of decision making of the concerned person. We become more disturbed whether autonomous decision should extend to sensitive and controversial issues such as the one we have. We also have to take cognizance of misuse of the available medical intervention by parents and individual who intentionally want to hide under the pretense of having a gender dyphoria. The worries of this paper can therefore be captured by this question: to what extent are individual said to be autonomous or are there limit to our freedom? Our conviction is that an individual has 
an autonomous right to do and make decision about his life and situation but this right should not be void of sanity. Issues about transgender do not necessitate surgery or other aggressive form of intervention. It is on this ground that this paper is proposing an alternative to total transexualism.

CONCLUSION: Transsexualism is a very controversial issue. It is controversial because one cannot argue that it harms the other person. For instance, a conscious effort to spread HIV to the other can be said to have a direct effect on the potential victim and also the society at large but transsexuals are satisfying their interests; getting themselves involve in aggressive intervention such as surgery and etc. in order to ensure they are in the body compatible with their gender identity. Yet, we are still worried about the problems generated by this practice, most especially, intervention in children who have the tendency of having a change of mind in the future. The irreversibility of this practice is also a good reason to be worried. Having seen the medical possibility of assisting the concerned individual and the risk it poses, it may be necessary to find an alternative to transsexualism, specifically SRS.

The alternative this paper suggests is to enter into a care relationship with the individual, listen to their worries and see ways in which they can be counseled and assisted. This cannot be successful if their pains and suffering are not shared with them. In fact, there may be need to acknowledge that their pains is evident; this will stimulate the process of interaction and it will help in the counseling process. Indeed, it is an issue that needs to be tackled in order to ensure that the processes and outcome of sexual and gender transcendence are not misused by individuals in the society (especially parents who prefer their child to be in the other body different from the so called natural body), medical practitioners, social crusaders among others. Moreover, there is a need for public discourse and public awareness on the fluidity in gender and sexual orientation so that people's attitude to this new development can be better sharpened. I am not morally convinced that the sole solution to this discomfort is total transition to the desired body or a change in gender status. In other words, the discomfort they claim to suffer is not a good reason to have sexual re-assignment.

\section{REFERENCES}

1. Hirschfeld M. Die intersexuallekonstitution, Sexualle Zwischentufen. 23: 2-27.

2. Ulrichs KH. Forschungenüber das Räthsel der mannmännlichenLiebe. Trans.1994. p. 1864-79.

3. Transgender, Transsexual, Gender Identity Disorder, http://www.web4health.info/en/answers/sexgender-what.htm.

4. Feinberg L. Transgender warriors, Boston: Beacon Press, 1996.

5. Feinberg L. Trans Liberation: Beyond Pink or Blue, Boston: Beacon Press; 1998, p. 43.

6. Kruijver FP, Zhou JN, Pool CW, Hofman MA, Gooren LJ, Swaab DF. Male-to-female transsexuals have female neuron numbers in a limbic nucleus. J Clin Endocrinol Metab 2000; 85(5): 2034-41.

7. Zhou JN, Hofman MA, Gooren LJG, Swaab DF. A sex difference in the human brain and its relation to transexuality. Nature 1995; 378(6552): 68-70.

8. Green R. A typical psychosexual development. In: Rutter M, Hersov L, Taylor E. eds. Child and adolescent psychiatry. London: Blackwell Scientific; 1994.

9. Zuckerand KS, Bradley SJ. Gender identity and psychosexual problems in children and adolescents. London: The Guilford Press; 1995.

10. Beauchamp TL, Childress JF. Principles of biomedical ethics. New York: Oxford University Press; 2009. p. 99. 
Bangladesh Journal of Bioethics 2012; 3(1):4-12

11. Rebecca K. Consciousness autonomy: displacing decisions in health care. Hasting Center Report 2005. p.34-44.

12. Jones WHS. Hippocrates. Vol. 1. Cambridge: Harvard University Press; 1923. p. 165.

13. Cohen-Keltenis PT, Pfafflin F. Transgenderism and intersexuality in childhood and adolescence, making choices. London: Sage Publication; 2003.

14. Baron J. Against bioethics. Cambridge: The MIT Press; 2006.

15. Finnis J. Natural law and natural rights. Oxford: Clarendon Press; 1980.

16. Elliot JS, Better than well. New York: Norton \& Co; 2003. 